\author{
vol.3 No.1 ISSN:18235-2016 \\ CRITICAL CARE NURSES' KNOWLEDGE AND PRACTICES \\ ABOUT SEPSIS BUNDLE AMONG CRITICALLY ILL \\ PATIENTS AT EMERGENCY HOSPITAL MANSOURA \\ UNIVERSITY \\ Mostafa M. Zanaty ${ }^{1 *}$; Warda Y. Morsy ${ }^{2}$; Karima F. Elshamy ${ }^{3}$; and \\ Shaimaa A. Ali1 \\ ${ }^{1,2,4}$ Critical Care and Emergency Nursing, Faculty of Nursing, Mansoura University, Egypt \\ ${ }^{3}$ Medical Surgical Nursing, Faculty of Nursing, Mansoura University, Egypt \\ *Email of the corresponding author: mostafazanaty22@yahoo.com
}

\begin{abstract}
:
Background: Literature review cited that, Sepsis is a common clinical condition associated with a high mortality rate among hospitalized patients and constitutes one of the main causes of death worldwide. Critical care nurses are the health care professionals who have the obligation to protect critically ill patients against infection especially that leading to sepsis, in order to enhance patients' recovery, prevent deterioration in their health, and provide high quality nursing care. Even so critical care nurses should have sound knowledge and strict adherence to sepsis bundle. Aim of the study: to assess nurses' knowledge and evaluate their practice regarding sepsis bundle. Research design: A descriptive exploratory research design was utilized in this study. Sample: A convenience sample that including 50 ICU nurses was recruited in the current study. Setting: The study was conducted at the Intensive Care Units at Emergency Hospital Mansoura University. Tools of data collection: Two tools were utilized, tested for clarity and viability, and then used to collect data pertinent to the study: Tool I: Structured Interview Questionnaire to assess nurses' knowledge regarding sepsis bundle. Tool II: Nurses' Practice Observational Checklist to evaluate nurses' practice regarding sepsis bundle. Results: the current study revealed that, approximately two-thirds $(68 \%)$ of the studied sample had unsatisfactory knowledge level $(<75 \%)$ with a mean total knowledge score of $(43.82 \pm$ $7.95)$. As well as, all studied sample $(100 \%)$ had unsatisfactory performance level $(<75 \%)$ with a mean total performance scores of $(59.58 \pm 5.7)$. Negative correlations were found between mean knowledge scores and mean practice scores; $(\mathrm{r}=0.1$ at $\mathrm{P}=0.5)$. Conclusion: Based on study findings, it can be revealed that critical care nurses had unsatisfactory knowledge and performance level regarding sepsis bundle. Recommendation: updating knowledge and performance of ICU nurses through continuing in-service educational programs; emphasizing the importance of following the latest evidence-based practices regarding sepsis bundle in continuing education / training programs; strict observation of nurses' performance and utilization of sepsis bundle and correction of poor practices are required; and providing training programs for newly joined ICU nurses about sepsis bundle and at regular intervals.
\end{abstract}

Key words: sepsis, sepsis bundle, intensive care unit (ICU), nurses' knowledge, nurses' practice.

\title{
Introduction:
}

Sepsis is one of the main causes of death in hospitalized patients and bowel cancer together, so far 
Dalia Masoud El-said et. al.

recognition of the problem still infection, they could refer to sepsis.

limited. Furthermore the The problem is known by having of

availability of advanced treatment methods, the mortality rate related to sepsis remains high, mainly due to miss diagnosis and tardy management ${ }^{(1)}$.

It is known as "a life-threatening problem that appears due to the body's response to infection", sepsis can infect any one and in any clinical setting. So, health care providers need to be conscious about its progression, how it can be diagnosed and the management that patients need ${ }^{(2)}$. Moreover sepsis is mainly caused by bacterial pathogenic micro-organisms; it can be caused by a fungal, viral source. Identification of infection can be detected easily as it affects the body's normal inflammatory response that causing physiological alterations which help in diagnosis. Systemic inflammatory response syndrome (SIRS) is a group of signs that the body is reacting to illnesses or injuries, and is not specific to infection. The body may react by increasing the heart or respiratory rate to compensate oxygen deficiency; or increasing white cell production to control infection.

Hyperglycemia and an altered mental state may be early manifestations of metabolic stress or hypoxia. Although these responses can be due to many reasons, when united with two or more SIRS criteria where infection is suspected or confirmed $^{(3)}$.

Sepsis causes complex dysfunction in the body's inflammatory and coagulopathy responses, leading to vasodilatation, vessel leakage and raised metabolic rate. This effect increases oxygen demand which, combined with intravascular leakage, leads to hypo-perfusion and ischemia at cellular levels. At this phase, severe sepsis clinical manifestations will raise (4). Identifying sepsis early is key to survival but is still the greatest challenge facing effective sepsis management. Nurses have a critical role in sepsis diagnosis especially through routine assessment. Patient who had with two or more SIRS and a suspected infective source is liable to have sepsis and needs closed monitoring for organ dysfunction manifestations ${ }^{(5)}$.

The majority of research evidence on sepsis is restricted to severe sepsis and septic shock there is little on uncomplicated sepsis. Patients with sepsis required rapid management to detect severity and prevent sepsis continuum. The use of sepsis management bundles is recommended by the SSC and other international sepsis forums. Management bundles bring together a small group of 
interventions that, when applied together and dependably, improve patient outcomes ${ }^{(6)}$.

Daniels et al (2010) developed the "Sepsis Six" management bundle, which was presented to improve delivery of care. Sepsis Six consists of three lab investigations and three actions that patients with sepsis should have within the first hour of diagnosis. Most of the interventions can be initiated by nursing staff while waiting for a medical attention, and guided help. If sepsis is suspected, complete blood count, coagulation profile, renal function, liver function tests, $\mathrm{C}$ - reactive protein and arterial blood gas (to ascertain lactate level) should be withdrawn. Haemoglobin deficiency will reduce the tissues perfusion so should be urgently diagnosed and managed, while an increased white cell count is infection indicator of and is used as part of the initial sepsis screening. An elevated lactate provides an indicator of metabolic compromise and development of severe sepsis ${ }^{(8)}$.

Blood cultures are recommended to improve microbial diagnosis to detect the suitable antibiotic therapy. Cultures should be done from different sites and should include one from each intravenous line in place for more than 48 hours. Cultures should also be done from other sources, as sputum or urine. Fluid balance is a good indicator of circulating volume and renal function, and therefore necessary for effective management of sepsis. Insertion of a urinary catheter is very important for accurate measurement of urinary output ${ }^{(8)}$.

Patients with sepsis need large amount of oxygen until proved otherwise. that no hypo-perfusion exists. Patients with chronic pulmonary disease should carefully assess for high oxygen levels tolerance ${ }^{(9)}$.Fluid resuscitation is essential to prevent hypotension and improve cardiac output and therefore tissue perfusion. The SSC currently recommends $30 \mathrm{ml} / \mathrm{kg}$ of crystalloids for patients with hypotension or raised lactate $(>4 \mathrm{mmol})$ Broad-spectrum antibiotics should be administered within the first hour of sepsis being diagnosed. Antibiotic therapy should repose on the possible infection source. Antibiotic therapy should be checked daily to reduce toxicity, risk of resistance and $\operatorname{cost}^{(7)}$.

Nurses are pivotal in spotting patients who are unwell, and in initiating life-saving management. Clear guidance on diagnosis and evidence-based practices is available to support effective and safe intervention (11). As well, studies that assess nurses' knowledge and practice about sepsis bundle are scares and needed. Therefore the present study 
aim to reveal to what extent nurses perform their role regarding sepsis bundle, hoping to develop and emphasize their role in the near future.

\section{Significance of the study}

Sepsis and septic shock account for approximately $10 \%$ of the admissions to intensive care units (ICU), and account for as many as $2.9 \%$ of all hospital admissions. The mortality rate has been identified to be between $28 \%$ and $50 \%$ with septic patients. Moreover, treating the patient after he or she has severe sepsis for the ICU increases the costs greater than six times that of an ICU patient who does not have sepsis ${ }^{(12,13)}$. Provision of such knowledge and practices related to sepsis bundle would be beneficial for nurses in different ways.

It could have a direct positive reflection upon the quality of patient care, and could support the important role of the nurse related to sepsis management. Also, it might generate an attention and motivation for further researches into this area. This improved patient's outcomes and shorten patient's length of ICU stay. Therefore, the current study was carried out to evaluate critical care nurses' knowledge and practices about sepsis bundle at Emergency Hospital Mansoura University.
Aim of the study:

The aim of this study was to assess nurses' knowledge and evaluate their practice about sepsis bundle among critically ill patients.

\section{Research questions:}

The following two research questions were formulated to achieve the aim of the current study:

Q1: what is the level of knowledge that the critical care nurses have about sepsis bundle?

Q2: what is the level of practice that the critical care nurses perform regarding sepsis bundle for critically ill patients?

\section{Material and Methods}

Materials:-

\section{Research Design:}

A descriptive exploratory research design was utilized in this study.

Setting:

This study was carried out at the critical Care Units (CCUs) of Emergency Hospital at Mansoura University.

\section{Subjects:}

A convenience sample of 50 female nurses who had at least one year of working experience in the ICUs and involved in providing direct care for critically ill patients in previously mentioned setting. The nurses that were participating voluntarily and gave consent were recruited in the study. 
EFFECT OF IMPLEMENTING EDUCATIONAL GUIDELINES ABOUT etc...

Tools:

Data were collected using two tools in order to achieve the aim of the study.

Tool one: Structured Interview Questionnaire. This tool was developed by the researcher after reviewing the recent related literatures; to assess critical care nurses'(CCNs') knowledge about sepsis bundle among critically ill patients; it consists of 63 questions in the form of multiple choice questions, and true / false questions. Additionally, tool I was initiated to collect sociodemographic characteristics of nurses such as age, educational level, years of working experience in the ICUs and attending training programs / workshops / scientific conferences regarding the care of patients with sepsis.

Scoring system: One score was allocated to each right answer and zero to the wrong answer. Scores of less than $75 \%$ are considered unsatisfactory; however scores of $75 \% \quad-100 \%$ are considered satisfactory ${ }^{(14)}$.

Tool two: Nurses' Practice Observational Checklist. This tool was adopted by Institute for Healthcare Improvement (2002), (Dellinger et al., 2004), then it was modified by the researcher to assess critical care nurses' practice about sepsis bundle among critically ill patients. This tool covering 5 main items with 96 subitems related to sepsis bundle.

Scoring system: One score was allocated to each correct performance and zero to incorrectly done, incompletely done, and not done performance. Scores less than $75 \%$ are considered unsatisfactory practices; however scores from 75 $\% \quad-100 \%$ are considered satisfactory ${ }^{(14)}$.

\section{Method:}

Administrative design:

The present study was approved by the Scientific Research Ethics Committee of the Faculty of Nursing Mansoura University .Approval permission to conduct the study was obtained from the hospital administrative personnel based on the official letter after explanation the aim and nature of the study. Informed consents were obtained from the nurses before the beginning of the study after explanation of the purpose and nature of the study.

Protection of human rights:

Ethical consideration approval was obtained from Scientific Research Ethics Committee of the Faculty of Nursing Mansoura University. The researcher explained to the participants that there was no risk or hazards related to the study. Privacy and confidentiality of the collected data were assured. Each participant was informed that his participation in 
the study was voluntary and they could withdraw at any stage without any responsibility.

Operational design:

This design involved the preparatory phase, pilot study, and fieldwork.

\section{Preparation phase}

This study involved two tools; tool I "Nurses' knowledge questionnaire" and tool II "Nurses' practice checklists ".

The researcher explained to nurses the aim and nature of the study and the time needed to answer the knowledge tool and collecting them. Tool I was developed into simple Arabic language by the researcher after reviewing of recent literature. Tool II was modified by the researcher to be suitable for the study after reviewing of recent literature to evaluate nurses' practice.

Tools validity and reliability:

Tools were examined for content validity by a panel of six experts in the field of Critical Care Medicine, and Critical Care and Emergency Nursing. Necessary modifications were done accordingly. The overall reliability of the tools was tested using $(\alpha)$ Cronbach test on a sample of 50 subjects and found to be $86 \%$.

Pilot study

A pilot study was carried out before starting data collection on five nurses $(10 \%)$ to test clarity, feasibility, applicability of the tools and time frame to answer the questionnaire. Based on the findings necessary modifications were done accordingly. Those nurses were excluded from the study.

Fieldwork

Assessment of CCNs' practices about sepsis bundle was done through indirect observation method using tool II, assessment of nurses' practices was done for three times in different shifts (morning, evening and night shifts) for each nurse participated in the study for evaluation (1st assessment, 2nd assessment and 3rd assessment) then those assessments were summed up to get the mean assessment score. An explanation about the aim and nature of the study was discussed with the head nurse and with CCNs staff in the CCUs.

Privacy and confidentiality were assured before the data collected. CCNs' knowledge about sepsis bundle was assessed, using self administered tool I questionnaire; the time average for completing the questionnaire ranged from 30-35 minutes.

\section{Statistical analysis}

Data entry and analysis was performed using the Statistical Package for Social Sciences version 16 (SPSS). Descriptive statistics, Correlation coefficient, Arithmetic mean, Standard deviation (SD), Chi square $\left(\chi^{2}\right)$, one 
EFFECT OF IMPLEMENTING EDUCATIONAL GUIDELINES ABOUT etc...

way ANOVA test and Paired sample $t$ - tests were used in the analysis. A significance level was considered at $\mathrm{P}$ value $=0.05$.

\section{Results:}

This part represents the current study findings concerning the nurses' knowledge and practices about the sepsis bundle among critically ill patients at Emergency hospital, Mansoura University. Findings of the present study, table (1) revealed that $(56 \%)$ of the study subjects were in the age group ranged between 30 and less than 40 years with a mean age of $(33.12 \pm$ 5.49 ), as regard to the level of education, more than two-thirds of the studied subjects (70\%) were secondary diploma nurses while the remainders $(24 \%$ and $6 \%)$ were bachelor and technical diploma nurses respectively.

As regarding years of experience in ICU, more than one-third of the studied subjects $(36 \%)$ were having experience between 15 and less than 20 years with mean years of experience of (14.56 \pm 5.38). Finally; in relation to attending training programs, workshops and scientific conferences, the majority of them (94\%) didn't attend.

Table (2) shows that the total mean knowledge scores of the studied subjects were (43.82 \pm $7.95)$ out of 63 . In relation to knowledge sub-items, the third subitem related to hemodynamic monitoring has got the highest mean score $(3.28 \pm 1.19)$ out of 4 , while sub-item related to therapeutic and maintained goals after ICU Admission has got the lowest mean score $(11.36 \pm 3.33)$ out of 17 .

Table (3) and figure (1): highlights that near two-thirds of the studied subjects $(68 \%)$ have got unsatisfactory knowledge level regarding sepsis bundle. As well as; all studied subjects $(100 \%)$ have got unsatisfactory knowledge level regarding therapeutic and maintained goals after ICU Admission. In addition to, more than three-quadrants of them $(76 \%$ and $76 \%$ ) have got unsatisfactory knowledge level regarding criteria for initiating the bundle as well laboratories and infection-control measures respectively.

Table (4): according to the table, the total mean practice scores of the studied subjects were $(59.58$ \pm 5.7 ) out of 96. In relation to practices sub-items, the fourth subitem related to treatment protocol and nursing management has got the highest mean score $(9.88 \pm$ 1.25 ) out of 14 , while sub-item related to criteria for initiating the bundle has got the lowest mean score $(0.5 \pm 0.8)$ out of 3 .

Table (5): shows that all studied subjects $(100 \%)$ have got an unsatisfactory practice level regarding sepsis bundle as well as regarding criteria for initiating the bundle. Moreover, most of the 
Dalia Masoud El-said et. al.

studied nurses (92\% and 88\%) have got unsatisfactory practice level, regarding therapeutic and maintained goals after ICU Admission and hemodynamic monitoring respectively.

Table (6): reflects that there is no significant statistical relation between the studied nurses' demographic characteristics in relation to their age, years of experience in ICU and attending training programs, workshops and scientific conference to total knowledge score, Except the education level where $(\mathrm{F}=4$, $\mathrm{P}=0.000$ ) as bachelor degree nurses has got the higher mean (54.9 \pm 5.3).

Table (7): reflects that there is no significant statistical relation between the studied nurses' demographic characteristics in relation to their age, the education level and attending training programs, workshops and scientific conference to total practice score, Except years of experience in ICU where $(\mathrm{F}=3, \mathrm{P}=0.04)$ as the nurses have experience ranged between 15 and less than 20 years that got the higher mean $(62.4 \pm 5.6)$.

Table (8) and figure (2): present correlation between total scores of nurses' knowledge and their total practice scores through the study periods. From this table, it can be concluded that there is no significant statistical correlation existed between total knowledge scores and total practice scores of nurses.

Table (1) : Socio-demographic characteristics' distribution of the study subjects

\begin{tabular}{|c|c|c|}
\hline \multirow[b]{2}{*}{ Variables } & \multicolumn{2}{|c|}{$\mathbf{N}=\mathbf{5 0}$} \\
\hline & No & $\%$ \\
\hline Age group (years) & & \\
\hline $20-<30$ & 13 & 26 \\
\hline $30-<40$ & 28 & 56 \\
\hline $40-\geq 50$ & 9 & 18 \\
\hline \multicolumn{3}{|l|}{ Mean \pm SD $\quad 33.12 \pm 5.49$} \\
\hline \multicolumn{3}{|l|}{ Educational level } \\
\hline BSc Nurses & 12 & 24 \\
\hline Technical Diploma Nurses & 3 & 6 \\
\hline Secondary Diploma Nurses & 35 & 70 \\
\hline Years of working experience in ICU by year & & \\
\hline $5-<10$ & 12 & 24 \\
\hline $10-<15$ & 13 & 26 \\
\hline $15-<20$ & 18 & 36 \\
\hline $20-\geq 25$ & 7 & 14 \\
\hline \multicolumn{3}{|l|}{ Mean \pm SD $14.56 \pm 5.38$} \\
\hline $\begin{array}{l}\text { Attending training programs / workshops / scientific } \\
\text { conferences reoarding the care of natients with sensis }\end{array}$ & & \\
\hline Yes & 3 & 6 \\
\hline No & 47 & 94 \\
\hline
\end{tabular}


EFFECT OF IMPLEMENTING EDUCATIONAL GUIDELINES ABOUT etc...

Table (2): Total and subtotal means knowledge scores regarding sepsis bundle among critically ill patients $(\mathrm{N}=50)$.

\begin{tabular}{|c|c|c|}
\hline Variable & Total score & mean \pm sd \\
\hline Total knowledge scores & 63 & $43.82 \pm 7.95$ \\
\hline & 11 & $7.36 \pm 1.48$ \\
\hline - Criteria for initiating the bundle & 17 & $11.8 \pm 2.98$ \\
\hline - Laboratories and infection-control & 4 & $3.28 \pm 1.19$ \\
\hline measures & 14 & $10.2 \pm 2.76$ \\
\hline - Hemodynamic monitoring & 17 & $11.36 \pm 3.33$ \\
\hline $\begin{array}{l}\text { Treatment protocol and Nursing } \\
\text { management }\end{array}$ & & \\
\hline $\begin{array}{l}\text { - Therapeutic and maintained goals after } \\
\text { ICU Admission. }\end{array}$ & & \\
\hline
\end{tabular}

Table (3): Total satisfaction level scores of nurses' knowledge regarding sepsis bundle $(\mathrm{N}=50)$

\begin{tabular}{|c|c|c|c|c|}
\hline Variable & $\begin{array}{l}\text { Total } \\
\text { score }\end{array}$ & No & $\%$ & $\begin{array}{c}\operatorname{mean} \pm \\
\text { sd }\end{array}$ \\
\hline $\begin{array}{l}\text { Total knowledge satisfaction } \\
-\quad \text { Unsatisfactory knowledge } \\
-\quad \text { Satisfactory knowledge }\end{array}$ & 63 & $\begin{array}{l}34 \\
16 \\
\end{array}$ & $\begin{array}{l}68 \\
32 \\
\end{array}$ & $\begin{array}{l}39.3 \pm 4 \\
53.4 \pm 5.3\end{array}$ \\
\hline $\begin{array}{l}\text { Criteria for initiating the bundle } \\
-\quad \text { Unsatisfactory knowledge } \\
-\quad \text { Satisfactory knowledge } \\
\end{array}$ & 11 & $\begin{array}{l}38 \\
12 \\
\end{array}$ & $\begin{array}{l}76 \\
24 \\
\end{array}$ & $\begin{array}{l}6.7 \pm 1 \\
9.4 \pm 0.7 \\
\end{array}$ \\
\hline $\begin{array}{l}\text { Laboratories and infection-control } \\
\text { measures } \\
-\quad \text { Unsatisfactory knowledge } \\
-\quad \text { Satisfactory knowledge } \\
\end{array}$ & 17 & $\begin{array}{l}38 \\
12\end{array}$ & $\begin{array}{l}76 \\
24\end{array}$ & $\begin{array}{l}10.2 \pm 1 \\
16.8 \pm 0.4\end{array}$ \\
\hline \begin{tabular}{ll}
\multicolumn{1}{l}{ Hemodynamic monitoring } \\
$-\quad$ Unsatisfactory knowledge \\
$-\quad$ Satisfactory knowledge \\
\end{tabular} & 4 & $\begin{array}{c}5 \\
45 \\
\end{array}$ & $\begin{array}{l}10 \\
90 \\
\end{array}$ & $\begin{array}{l}0 \pm 0 \\
3.6 \pm 0.5\end{array}$ \\
\hline $\begin{array}{l}\text { Treatment protocol and Nursing } \\
\text { management } \\
-\quad \text { Unsatisfactory knowledge } \\
-\quad \text { Satisfactory knowledge }\end{array}$ & 14 & $\begin{array}{l}26 \\
24\end{array}$ & $\begin{array}{l}52 \\
48\end{array}$ & $\begin{array}{l}7.8 \pm 1.9 \\
12.4 \pm 1\end{array}$ \\
\hline $\begin{array}{l}\text { Therapeutic and maintained goals } \\
\text { after ICU Admission } \\
\text { - Unsatisfactory knowledge } \\
-\quad \text { Satisfactory knowledge }\end{array}$ & 17 & $\begin{array}{c}50 \\
0 \\
\end{array}$ & $\begin{array}{c}100 \\
0\end{array}$ & $\begin{array}{l}7.7 \pm 10.7 \\
0 \pm 0\end{array}$ \\
\hline
\end{tabular}


Dalia Masoud El-said et. al.

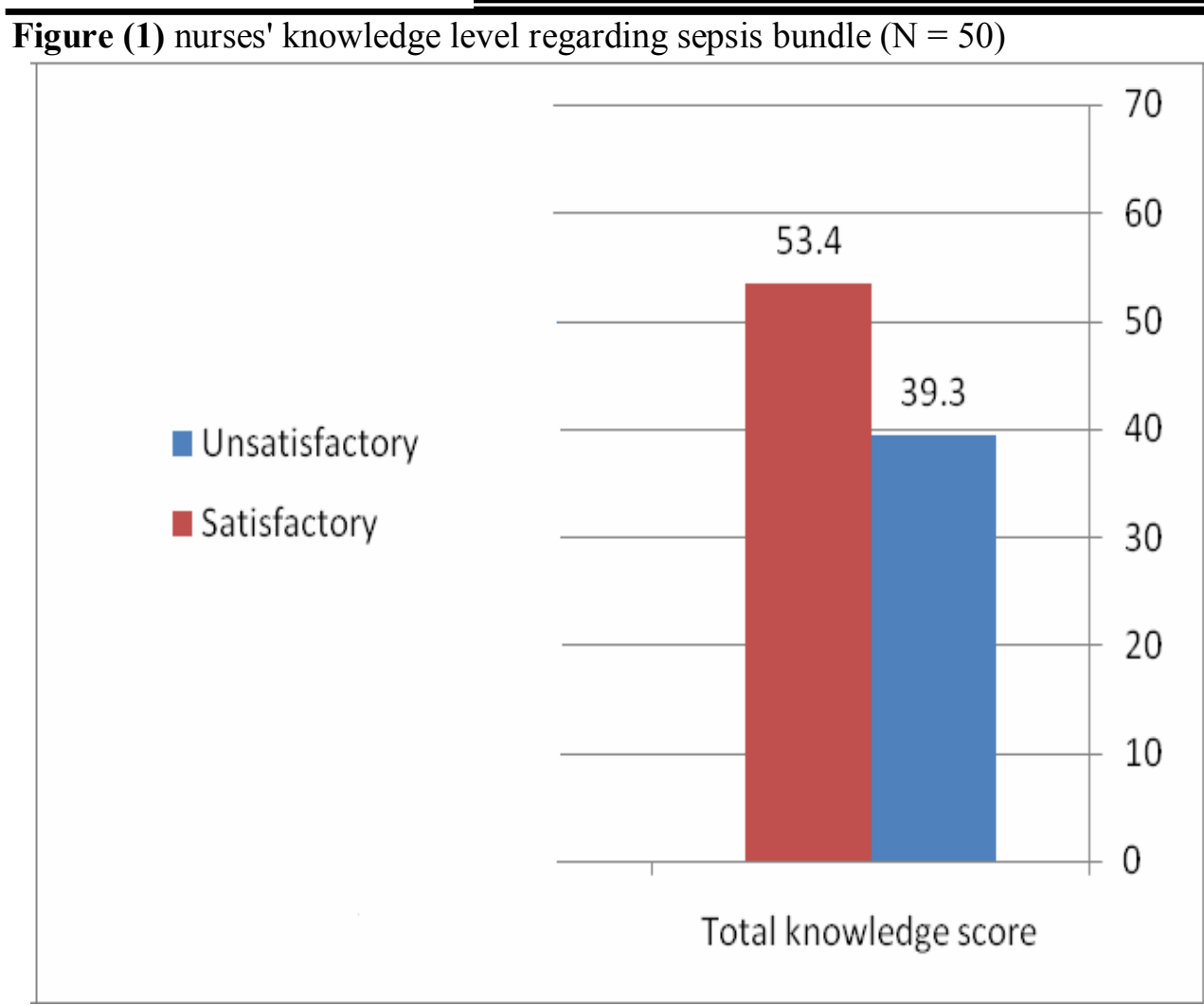

Figure (1): chart for the distribution of total knowledge satisfaction

Table (4): Total and subtotal means practices scores regarding sepsis bundle among critically ill patients $(\mathrm{N}=50)$

\begin{tabular}{|c|c|c|}
\hline Variable & $\begin{array}{l}\text { Total } \\
\text { score }\end{array}$ & Mean \pm sd \\
\hline $\begin{array}{l}\text { Total practice score } \\
\text { - Criteria for initiating the bundle } \\
\text { - Laboratories and infection-control measures } \\
\text { - Hemodynamic monitoring } \\
-\quad \text { Treatment protocol and Nursing } \\
\text { management } \\
\text { - Therapeutic and maintained goals after ICU } \\
\text { Admission. }\end{array}$ & $\begin{array}{c}6 \\
3 \\
36 \\
30 \\
14 \\
13\end{array}$ & $\begin{array}{c}59.58 \pm 5.7 \\
0.5 \pm 0.8 \\
21.8 \pm 4.1 \\
19.96 \pm 1.94 \\
9.88 \pm 1.25 \\
7.4 \pm 1.53\end{array}$ \\
\hline
\end{tabular}


EFFECT OF IMPLEMENTING EDUCATIONAL GUIDELINES ABOUT etc...

Table (5): Total satisfaction scores levels of critical care nurses' practice related to sepsis bundle $(\mathrm{N}=50)$

\begin{tabular}{|c|c|c|c|c|}
\hline Variable & $\begin{array}{l}\text { Total } \\
\text { score }\end{array}$ & No & $\%$ & mean $\pm s d$ \\
\hline $\begin{array}{l}\text { Total practice satisfaction } \\
\text { - } \quad \text { Unsatisfactory Practice } \\
\text { - } \quad \text { Satisfactory Practice }\end{array}$ & 96 & $\begin{array}{c}50 \\
0 \\
\end{array}$ & $\begin{array}{c}100 \\
0\end{array}$ & $\begin{array}{c}59.6 \pm 5.7 \\
0 \pm 0\end{array}$ \\
\hline $\begin{array}{l}\text { Criteria for initiating the bundle } \\
-\quad \text { Unsatisfactory Practice } \\
-\quad \text { Satisfactory Practice }\end{array}$ & 3 & $\begin{array}{c}0 . \\
---\end{array}$ & $\begin{array}{l}100 \\
---\end{array}$ & $\begin{array}{c}0.5 \pm 0.8 \\
----\end{array}$ \\
\hline $\begin{array}{l}\text { Laboratories and infection-control } \\
\text { measures } \\
\text { - Unsatisfactory Practice } \\
\text { - } \quad \text { Satisfactory Practice }\end{array}$ & 36 & $\begin{array}{l}39 \\
11 \\
\end{array}$ & $\begin{array}{l}78 \\
22 \\
\end{array}$ & $\begin{array}{c}20 \pm 2.4 \\
28.5 \pm 1.1 \\
\end{array}$ \\
\hline $\begin{array}{l}\text { Hemodynamic monitoring } \\
\text { - } \quad \text { Unsatisfactory Practice } \\
\text { - } \quad \text { Satisfactory Practice } \\
\end{array}$ & 30 & $\begin{array}{c}44 \\
6 \\
\end{array}$ & $\begin{array}{l}88 \\
12 \\
\end{array}$ & $\begin{array}{l}19.5 \pm 1.6 \\
23.3 \pm 0.5 \\
\end{array}$ \\
\hline $\begin{array}{l}\text { Treatment protocol and Nursing } \\
\text { management. } \\
\text { - Unsatisfactory Practice } \\
\text { - Satisfactory Practice }\end{array}$ & 14 & $\begin{array}{l}38 \\
12\end{array}$ & $\begin{array}{l}76 \\
24\end{array}$ & $\begin{array}{c}9.3 \pm 0.8 \\
11.6 \pm 1\end{array}$ \\
\hline $\begin{array}{l}\text { Therapeutic and maintained goals } \\
\text { after ICU Admission. } \\
\text { - Unsatisfactory Practice } \\
\text { - Satisfactory Practice }\end{array}$ & 13 & $\begin{array}{c}46 \\
4\end{array}$ & $\begin{array}{c}92 \\
8\end{array}$ & $\begin{array}{c}7.2 \pm 1.3 \\
10.3 \pm 0.5\end{array}$ \\
\hline
\end{tabular}


Dalia Masoud El-said et. al.

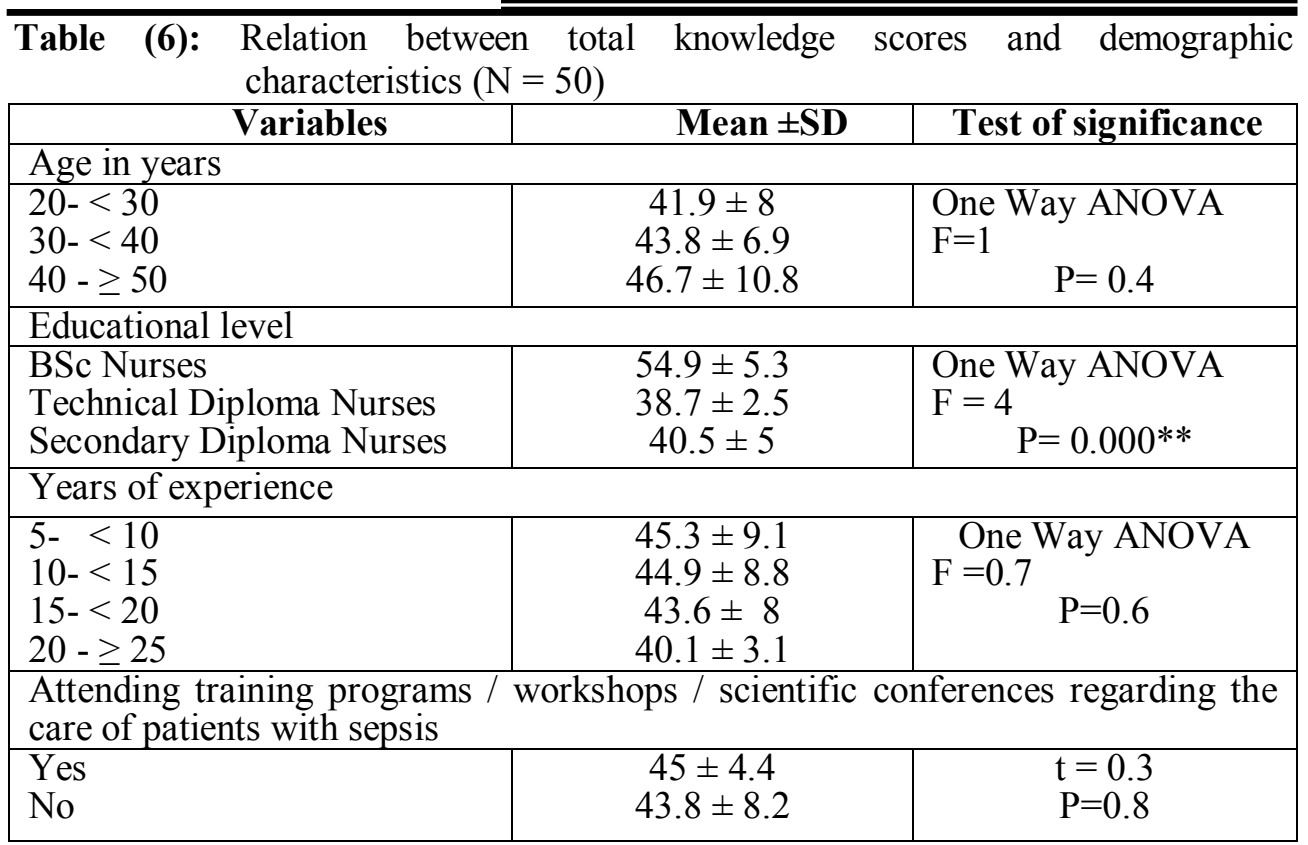

** Highly statistical significant difference $(\mathrm{P}<0.001)$

$*_{\text {statistical significant difference }(\mathrm{P}<0.05)}$

Table(18):Relation between total practice score and demographic characteristics

\begin{tabular}{|c|c|c|}
\hline Variables & Mean \pm SD & Test of significance \\
\hline \multicolumn{3}{|l|}{ Age in years } \\
\hline $\begin{array}{l}20-<30 \\
30-<40 \\
40-\geq 50\end{array}$ & $\begin{array}{l}58.2 \pm 4.8 \\
60.4 \pm 5.8 \\
59 \pm 6.7\end{array}$ & $\begin{array}{l}\text { One way ANOVA } \\
\mathrm{F}=0.7 \\
\qquad \mathrm{P}=0.5\end{array}$ \\
\hline \multicolumn{3}{|l|}{ Educational level } \\
\hline $\begin{array}{l}\text { BSc Nurses } \\
\text { Technical Diploma Nurses } \\
\text { Secondary Diploma Nurses }\end{array}$ & $\begin{array}{l}61.2 \pm 7.6 \\
58.7 \pm 2.9 \\
59.6 \pm 5.2\end{array}$ & $\begin{array}{l}\text { One way ANOVA } \\
\mathrm{F}=.6 \quad \mathrm{P}=0.6\end{array}$ \\
\hline \multicolumn{3}{|l|}{ Years of experience } \\
\hline $\begin{array}{l}5-<10 \\
10-<15 \\
15-<20 \\
20-\geq 25\end{array}$ & $\begin{array}{l}59.2 \pm 5.7 \\
57 \pm 5.3 \\
62.4 \pm 5.6 \\
57.7 \pm 4.4\end{array}$ & $\begin{array}{l}\text { One way ANOVA } \\
\mathrm{F}=3 \quad \mathrm{P}=0.04^{*}\end{array}$ \\
\hline \multicolumn{3}{|c|}{$\begin{array}{l}\text { Attending training programs / workshops / scientific conferences regarding the } \\
\text { care of patients with sepsis }\end{array}$} \\
\hline $\begin{array}{l}\text { Yes } \\
\text { No }\end{array}$ & $\begin{array}{l}61.7 \pm 3.8 \\
59.5 \pm 5.8\end{array}$ & $\begin{array}{l}\mathrm{t}=0.7 \\
\mathrm{P}=0.5\end{array}$ \\
\hline
\end{tabular}

** Highly statistical significant difference $(\mathrm{P}<0.001)$

*statistical significant difference $(\mathrm{P}<0.05)$ 
EFFECT OF IMPLEMENTING EDUCATIONAL GUIDELINES ABOUT etc...

Table (19) correlation between total score of knowledge and total score of practice of studied nurses $(\mathrm{N}=50)$

\begin{tabular}{|l|c|c|}
\hline \multirow{2}{*}{ Variable } & \multicolumn{2}{c|}{ Total Practice score } \\
\cline { 2 - 3 } & r & P value \\
\hline Total knowledge score & 0.1 & 0.5 \\
\hline
\end{tabular}

** Highly statistical significant difference $(\mathrm{P}<0.001)$

*statistical significant difference $(\mathrm{P}<0.05)$

Figure (2): Correlation between total scores of nurses' knowledge and their total practice scores all through the study periods.

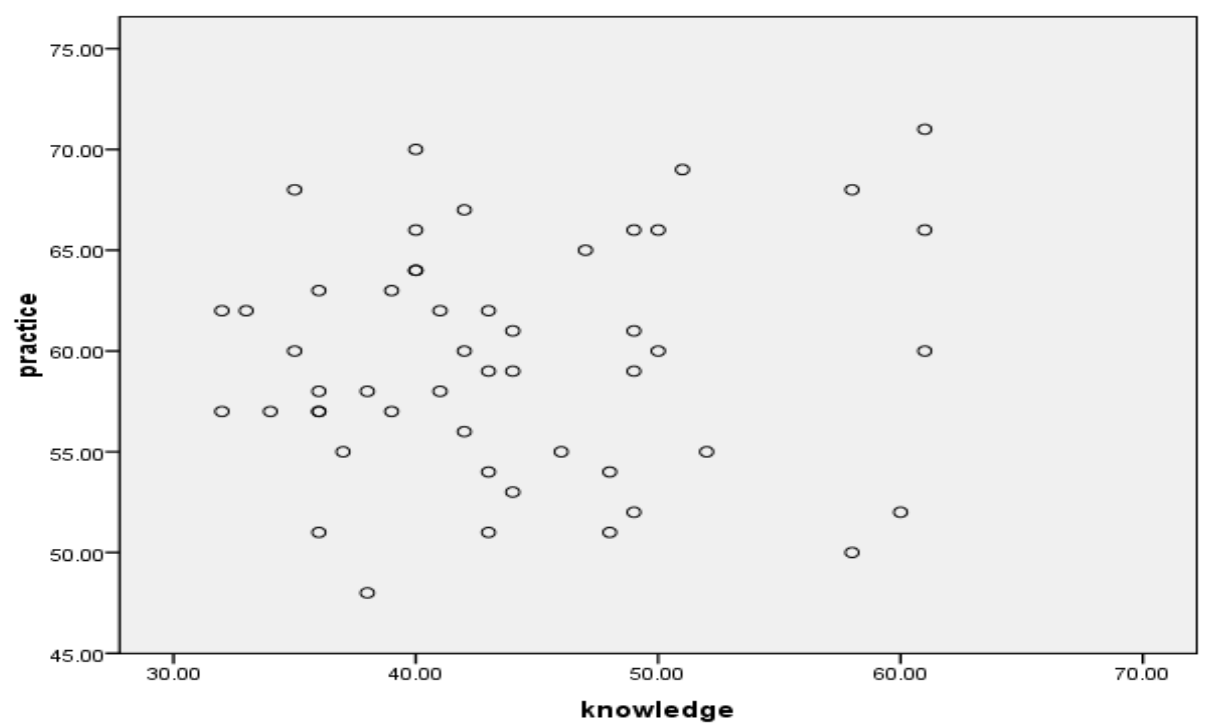

Figure (2): Scatter diagram for correlation between knowledge and practice scores

\section{Discussion}

The present study findings are discussed in reference to the aims and research questions of the study. Regarding to subjects sociodemographic characteristics, the total number of the current studied sample was 50 nurses; near three quadrants of them (70\%) carrying diploma nursing degree. It may be due to the majority of Egyptian nurses were graduate of secondary nursing schools This finding is contradicted with Jeffery, et al $(2014)^{(15)}$ who carried out research about knowledge and recognition of SIRS and sepsis among pediatric nurses on 242 nurses and the study revealed that $(57 \%)$ of nurses carrying baccalaureate degree. 
Dalia Masoud El-said et. al.

Similarly, Houston Methodist Hospital (2014) $)^{(16)}$ which carried out research entitled early recognition and rapid intervention of sepsis on 53 nurses and this study revealed that majority of nurses $\quad(84.9 \%) \quad$ carrying baccalaureate degree. but this result was supported by Salama (2002) ${ }^{(17)}$ and Wilson $(2007)^{(18)}$ who commented that more than half of nurses had got diploma in nursing comparing with little number of nurses had got bachelors' degree in nursing science In relation to age and years of experience, more than half of the nurses their age ranged between 30 and less than 40 with the mean $(33.12 \pm 5.49)$ and more than one third of them having 15 to less than 20 years of working experience in the ICU with the mean $(14.56 \pm 5.38)$.

Concerning attendance training programs / workshops / scientific conferences regarding the care of patients with sepsis; majority of studied sample $(94 \%)$ did not attend. This may be due to lack of in-service training programs which are very important in improving quality of care regarding patient with sepsis. This result was in harmony with Harper $(2007)^{(19)}$, who found that only $15 \%$ of emergency nurses reported that they had participated in continuing education on evidence-based ischemic stroke care.
But, These findings are contradicted with Eskander et al. $(2013)^{(20)}$ who revealed that most of the studied nurses were in the age group of 20-29 with the mean (27.81 4 4.64), had bachelor degree in percentages of $(76.6 \%, 66.2 \%$ and $81.8 \%$ ) respectively. Moreover, more than half of them $(50.6 \%)$ had less than five years of experience with the mean $(6.37 \pm 5.39)$. But, in the same line with him regarding attendance of training courses as around two thirds of the studied sample $(63.6 \%)$ never attends any continuing education courses.

Nurses' knowledge about sepsis bundle among critically ill patients at Mansoura Emergency University Hospital.

To fulfill the aim of this study, two questions were formulated and tested. Findings of this study supported the two started questions. the finding data that answered the first research question regarding nurses' knowledge about sepsis bundle "what is the level of knowledge that the critical care nurses have about sepsis bundle?" revealed that two-thirds of the studied subjects $(68 \%)$ have got unsatisfactory knowledge level with the mean $(39.3 \pm 4)$ out of 63 scores, this finding supported by Jeffery, et al (2014) ${ }^{(15)}$ who carried out research about knowledge and recognition of SIRS and sepsis among pediatric nurses revealed that a significant knowledge deficit 
among participants with the mean $(30.4 \pm 3.7)$ out of 50 items.

And Houston Methodist Hospital $(2014)^{(16)}$ which carried out research entitled early recognition and rapid intervention of sepsis and this study revealed that $(62 \%)$ have got unsatisfactory knowledge level with the mean $(9.32 \pm 1.97)$ out of 15 scores. similarly, Poeze, et al. $(2004)^{(21)}$ who carried out An international sepsis survey: a study of doctors' knowledge and perception about sepsis revealed that two-thirds $(67 \%)$ of the studied sample were concerned that a common definition is lacking and $(83 \%)$ of them have got unsatisfactory knowledge level regarding sepsis diagnosing.

The study finding is in the same line with Fernández et al. (2007) ${ }^{(22)}$ who revealed that the sample population level of knowledge quite poorly, with a mean of less than $(50 \%)$ correct answers. As well Nguyen et al. (2009) ${ }^{(23)}$ who carried out a study entitled educational course including medical simulation for early goaldirected therapy and the severe sepsis resuscitation bundle, revealed that the pre-test mean scores $(57.5 \pm 13.0)$. And also with Yousefi et al. $(2012)^{(24)}$ who carried out a research about reviewing the effects of an educational program about sepsis care on knowledge, attitude, and practice of nurses in intensive care units, revealed that in the pre-test results mean score of knowledge was $(64.5 \%)$

The researcher interpreted the reasons that may have relevance to the lack of knowledge pertinent to sepsis bundle for nurses in their clinical practice settings, lack of protocols and guidelines on sepsis bundle, curriculum gaps during training, lack of funding for organizing regular workshops; and negative attitude of nurses whereby new information learned at workshops was not readily applied in clinical practice.

Nurses' practices about sepsis bundle among critically ill patients at Mansoura Emergency University Hospital.

This part is specified to verify the second research question related to nurses' practices about sepsis bundle "what is the level of practice that the critical care nurses perform regarding sepsis bundle for critically ill patients?" revealed that all the study subjects $(100 \%)$ have got unsatisfactory level of practices with the mean $(59.6 \pm$ 5.7) out of (96) scores. The current study finding agreed with Tromp et al. (2010) (25) who carried out research about the role of nurses in the recognition and treatment of patients with sepsis in the emergency department revealed that only $(3.5 \%)$ of the studied sample performed the complete sepsis bundle. 
On contradictory with Yousefi et al. (2012) $)^{(24)}$ who carried out a research about reviewing the effects of an educational program about sepsis care on knowledge, attitude, and practice of nurses in intensive care units, revealed that in the pre-test results mean score of practices was $(81.8 \%)$.

The researcher may interpret this low practice level due to lack of education, lack of supervision, lack of continuous evaluation of nurses performance, lack of cooperation between multidisciplinary health team members (nurses physician), increased number of patient, and nurses' work load. In addition to the nurses' practices were based on traditions and imitations.

The correlation between nurses' total knowledge score and total practice score.

Findings of the present study reported that there is no significant statistical relation between the studied nurses' demographic characteristics in relation to their age, years of experience in ICU and attending training programs, workshops and scientific conference to total knowledge score. This study finding agreed with Ali $(2013)^{(26)}$, but, disagreed with Eskander et al. (2013) ${ }^{(20)}$ who revealed that significant statistical differences were found in mean knowledge scores only in relation to age and years of experience $(\mathrm{t}=$
2.52 and 2.40) at $p<0.05(0.014$ and 0.018 ) respectively.

The present findings showed there were highly significant statistical differences among nurses by their educational categories regarding knowledge where $(\mathrm{F}=4$, $\mathrm{P}=0.000)$ as the bachelor nurses have got the higher mean knowledge scores than secondary diploma and technical diploma nurses. This study finding supported by Eskander et al. $(2013)^{(20)}$ who revealed that the bachelor nurses have got the higher mean knowledge scores as compared to the other two groups (diploma and diploma with specialty) where $(\mathrm{F}=7.42$, $\mathrm{P}=0.001$ ).

In the present study there is no significant statistical relation between the studied nurses' demographic characteristics in relation to their age, educational level and attending training programs, workshops and scientific conference to total practice score. This study finding agreed with Ali (2013) (26), but, contradicted partially with Eskander et al. (2013) (20) who revealed that significant statistical differences were found in mean performance scores in relation to age where $(\mathrm{t}=$ $3.22)$ at $\mathrm{p}<0.05$ (0.002).

The present findings showed there were significant statistical differences among nurses by their years of experience in ICU and 
total practice score where $(\mathrm{F}=3$, $\mathrm{P}=0.04)$ as the nurses have experience ranged between 15 and less than 20 years that got the higher mean $(62.4 \pm 5.6)$. As the bachelor nurses have got the higher knowledge scores than secondary diploma and technical diploma nurses. This study finding supported partially by Eskander et al. $(2013)^{(20)}$ who revealed that significant statistical differences were found in mean performance scores in relation to years of experience where $(\mathrm{t}=2.99)$ at $\mathrm{p}<$ 0.05 (0.004). Also this result was supported by Harper (2007) ${ }^{(19)}$ who documented that there was a significant relation between number of years worked in emergency nursing as a specialist nurse and test scores, nurses with more years experience in emergency nursing had higher test scores.

The researcher examined the relationship between total mean knowledge and total mean practices scores regarding sepsis bundle. It revealed that there was no significant statistical correlation total mean knowledge and total mean practices scores. This finding agreed with Ali $(2013)^{(26)}$, but, contradicted with Eskander et al. $(2013)^{(20)}$ who revealed that positive correlation was found between mean knowledge scores and mean practice scores.

\section{Conclusion}

The findings of this study show that there is lack in nurses' knowledge and practices regarding sepsis bundle. There was a lack of educational materials, policies and protocol about sepsis bundle in the intensive care units. Therefore it will be imperative to establish a written updated protocol about sepsis bundle to ensure enough knowledge and safe nursing practice.

\section{Recommendations}

Based on the results of the present study the following recommendations are suggested:-

1. Provide nurses with continuous educational programs with evidence based guidelines to improve their knowledge and practice regarding sepsis bundle among critically ill patients.

2. Provide nurses with periodic training sessions to improve their practices regarding sepsis bundle among critically ill patients.

3. Develop nursing curriculum included theoretical topics and practical sessions about the sepsis bundle for different nursing categories (BSc Nurses, Technical Diploma Nurses and Secondary Diploma Nurses).

4. Sepsis bundle should be included partially in the patient's assessment sheet. 
Dalia Masoud El-said et. al.

5. Handling of barriers to sepsis bundle application among critically ill patients

Further Research:

- Similar study is recommended to include large sample size in other hospitals which provide care for sepsis bundle to confirm these findings.

- Further research is recommended to evaluate which teaching method and curriculum content are most effective to educate nurses caring for sepsis bundle and to identify barriers to incorporating this knowledge in practice.

\section{References}

1. Daniels, R. (2011). Surviving the first hours in sepsis: getting the basics right (an intensivist's perspective). Journal of Antimicrobial Chemotherapy; 66: 2, ii11-ii23.

2. Czura, C. (2011). sepsis speaking with one voice. Molecular Medicine; 17: 1-2.

3. Survive Sepsis Organisation (2009). Survive Sepsis: The Official Educational Programme of the Surviving Sepsis Campaign. Sutton Cold field: Survive Sepsis.Woodrow, P. (2012). Intensive Care Nursing. London: Routledge.

4. Porth,

M.

(2005).

Pathophysiology: Concepts of Altered Health States.
Philadelphia PA: Lippincott Williams \& Wilkins.

5. Slade, E. (2003). The Surviving Sepsis Campaign: raising awareness to reduce mortality. Critical Care; 7, 1-2.

6. Institute for Healthcare Improvement (2012). Using Care Bundles to Improve Health Care Quality.

7. Dellinger, R.; Levy, M. and Carlet, J. (2013). surviving sepsis campaign: international guidelines for management of severe sepsis and septic shock. Critical Care Medicine; 41: 2, 580-637.

8. Daniels, R. (2010). The sepsis six and the severe sepsis resuscitation bundle: a prospective observational cohort study. Emergency Medicine Journal; 28: 507-512.

9. O'Driscoll, B. (2008). On behalf of the British Thoracic Society. Guideline for emergency oxygen use in adult patients. Thorax; 63: vil-vi68.

10. McClelland, H. (2007). Can care bundles improve quality in emergency care? Accident and Emergency Nursing; 15: 119120.

11. Rivers, E.; McIntyre, L.; Morro, D. and Rivers, $K$. (2005). Early and innovative interventions for severe sepsis and septic shock: Taking advantage of a window of opportunity. Canadian Medical 
Association Journal; 173(9), 1054-1065.

12. Ahrens, T. and Tuggle, D. (2004). Surviving severe sepsis: Early recognition and treatment. Critical Care Nurse, Supplement; 24: 15.

13. Eskander, H.; Morsy, W. and Elfeky, H. (2013). Intensive Care Nurses' Knowledge and Practices regarding Infection Control Standard Precautions at a Selected Egyptian Cancer Hospital, Master Thesis at Cairo University, Journal of Education and Practice;4(19):160-174

14. Jeffery, A.; Mutsch, K. and Knapp, L. (2014). Knowledge and Recognition of SIRS And Sepsis among Pediatric Nurses;40(6):271-278

15. Houston Methodist Hospital (2014). Early recognition and rapid intervention of sepsis: Implementation of a focused educational initiative emphasizing early goal-directed therapy in the emergency department, Journal of Nursing Education and Practice; 4(6): 23-29

16. Salama, R. (2002). Assessment of Nurses Role in Reliving Abdominal Pain Using Non Pharmacological Measures, Master Thesis in Medical Surgical Nursing, Faculty of Nursing, Ain Shams University, Egypt; p: 92-98
17. Wilson, B. (2007). Issues in Clinical Care Nursing. Nurses Knowledge of Pain, Nursing Journal; 16(3): 1012-1020

18. Harper, J. (2007). Emergency Nurses' Knowledge of Evidence-Based Ischemic Stroke Care: A Pilot Study Emergency Nurses Association. Journal of Emergency Nursing; 43 (33): 202-7.

19. Eskander, H.; Morsy, W. and Elfeky, H. (2013). Intensive Care Nurses' Knowledge and Practices regarding Infection Control Standard Precautions at a Selected Egyptian Cancer Hospital, Master Thesis at Cairo University, Journal of Education and Practice;4(19):160-174

20. Poeze,M.; Ramsay, G.; Gerlach, H.; Rubulotta, F. and Levy, M. (2004). An international sepsis survey: a study of doctors' knowledge and perception about sepsis, Critical Care, 8:R409-R413

21. Fernández, R.; Galera, A.; Rodríguez, W.; Mora, E. and Vega, G. (2007). Sepsis: A Study of Physician's Knowledge about the Surviving Sepsis Campaign in Puerto Rico, Critical Care and Shock ; 4 (10): 131-141

22. Nguyen, B.; DanielUnderwood, L.; Ginkel, C.; Wong, M.; Lee, D.; Lucas, A.; Palaganas, J.; Banta, D.;. 
Denmark, T. and Clem, $K$. (2009). An educational course including medical simulation for early goal-directed therapy and the severe sepsis resuscitation bundle, Resuscitation; (80): 674-679

23. Yousefi, H.; Nahidian, M. and Sabouhi, F. (2012). Reviewing the effects of an educational program about sepsis care on knowledge, attitude, and practice of nurses in intensive care units; 17(2): S91-S95.

24. Tromp, M.; Hulscher, M.; Bleeker-Rovers, C.; Peters, L.; Berg, D.; Borm, G.;
Kullberg, B.; Achterberg, T. and Pickkers, P . (2010). the role of nurses in the recognition and treatment of patients with sepsis in the emergency department: A prospective before and after intervention study, International Journal of Nursing Studies; (47) :14641473.

25. Ali, N. (2013). Critical Care Nurses' Knowledge and Compliance with Ventilator Associated Pneumonia Bundle at Cairo University Hospitals; 4(15): 66-77. 